\title{
SELEÇÃO DE PROGÊNIES DE IRMÃOS GERMANOS DESTINADAS À PRODUÇÃO DE MILHO-VERDE
}

\section{SELECTION OF FULL-SIB FAMILIES FOR FRESH MARKET CORN PRODUCTION}

\author{
Rodrigo FERREIRA ${ }^{1}$ \\ José Raulindo GARDINGO 2 \\ Rodrigo Rodrigues MATIELLO ${ }^{3}$
}

\begin{abstract}
RESUMO
Com o objetivo de selecionar genótipos superiores de milho-verde, foram avaliadas 369 progênies de irmãos germanos, na safra de 2005/2006 na Fazenda Escola Capão da Onça da Universidade Estadual de Ponta Grossa. As parcelas foram constituídas de linhas de $4 \mathrm{~m}$ de comprimento, espaçadas $0,8 \mathrm{~m}$ entre si, com uma população de 50.000 plantas ha-1. Utilizou-se o delineamento de blocos casualizados com 3 repetições para as progênies derivadas das 190 maiores espigas secas e 2 repetições para as 179 espigas intermediárias. Foram avaliadas 5 espigas de cada progênie quanto a massa, comprimento e diâmetro com e sem palha. As espigas também foram avaliadas visualmente e calculada a correlação entre as características. Foi estimada a herdabilidade para todas as características avaliadas nas espigas colhidas no ponto de milho-verde. Houve diferenças significativas entre as progênies para todas as características avaliadas, ocorrendo grande número de progênies com performance similar aos híbridos. Observou-se correlação de média a alta para a maioria dos caracteres avaliados nas espigas de milho-verde. A herdabilidade estimada variou de 0,46 para diâmetro de espiga sem palha a 0,60 para o comprimento de espigas com palha. O ensaio com 190 progênies gerou $17,37 \%$ de progênies contendo espigas de milho-verde excelentes, enquanto que o ensaio com 179 progênies resultou em 3,91\% de espigas excelentes pelo aspecto visual. A proporção de progênies excelentes aumentou de $2,85 \%$ para $27,56 \%$ com um ciclo de seleção de irmãos germanos.

Palavras-chave: Teste de progênies; herdabilidade; população; Zea mays L.
\end{abstract}

\begin{abstract}
Progeny tests were conducted at the Agricultural Experiment Station of the State University of Ponta Grossa throughout the 2005-2006 growing seasons, aiming at evaluating 369 full-sib families. The plots of the trials consisted of rows with a 4 m-length, spaced of $0.8 \mathrm{~m}$ between rows, with a population density of 50.000 plants ha ${ }^{-1}$. A completely randomized block design was used for progenies derived from 190 large and dry ears with 3 replicates, and for 179 intermediate ears with two replicates. The following characteristics of five ears of each progeny were assessed: mass, length and diameter of the ears with and without straw. A visual observation on the ears as to its general aspect has also been adopted herein. The correlations between these characteristics and the heritability for all characteristics evaluated on the harvested ears were estimated. There were significant differences among progenies for all response variables analyzed, with a great number of progenies showing a performance similar to the hybrids. The correlation between the characteristics of the ears at fresh market stage was found to be variable from medium to high. The estimated heritability varied from 0.46 for diameter of the ears without straw treatment to 0.60 for length of the ears with straw. The trial carried out with 190 progenies generated $17.37 \%$ of excellent ears, whereas that one comprised by 179 progenies resulted in $3.91 \%$ of excellent progenies ears as to its visual appearance. The proportion of excellent ears increased from $2.85 \%$ to $27.56 \%$ within a single selection cycle of full-sib progenies.
\end{abstract}

Key-words: Progeny test; heritability; population; Zea mays L.

1 Engenheiro Agrônomo, Bolsista PIBIC/CNPq/Universidade Estadual de Ponta Grossa (UEPG), Ponta Grossa - PR, Brasil. E-mail: rfagronomy@hotmail.com.

2 Engenheiro Agrônomo, Doutor em Genética e Melhoramento de Plantas, Professor do Departamento de Fitotecnia e Fitossanidade da Universidade Estadual de Ponta Grossa. Avenida General Carlos Cavalcanti, 4748, Uvaranas, Ponta Grossa - PR, CEP: 84030-900. Brasil. E-mail: jrgardin@uepg.br. Autor para correspondência.

3 Engenheiro Agrônomo, Doutor em Genética e Melhoramento de Plantas, Professor do Departamento de Fitotecnia e Fitossanidade da Universidade Estadual de Ponta Grossa, Ponta Grossa - PR, Brasil. E-mail: rrmatiel@uepg.br. 


\section{INTRODUÇÃO}

O milho-verde (Zea mays L.) é consumido, em todo o Brasil, assado, cozido, ou como ingrediente de bolos, doces, sorvetes, pamonhas, etc. Devido ao seu elevado teor de umidade $(70 \%$ a $80 \%$ umidade) é um produto altamente perecível, cuja qualidade depende de plantios sucessivos ao longo do ano, precisão do produtor na colheita e rapidez na comercialização. Ao contrário dos EUA e Canadá, a maioria dos genótipos cultivados no Brasil é de milho comum, sendo o milho doce utilizado principalmente pela indústria de enlatados (Paiva Júnior et al., 2001; Rodrigues, 2007).

Por ser uma cultura com boa lucratividade, o cultivo de milho-verde vem crescendo em todo o país, produzindo na safra 1995/96 cerca de $292.000 \mathrm{t}$ de espigas em 102.325 ha, com produção concentrada principalmente nos estados de Minas Gerais, São Paulo, Goiás, Paraná, e o maior volume consumido no estado de São Paulo (Tsunechiro et al., 2003). Com o emprego de nível tecnológico e genótipos adequados, a produtividade de espigas comerciais com palha é superior a $9 \mathrm{t} \mathrm{ha}^{-1}$ (Paiva Júnior et al., 2001; Pereira Filho et al., 2003).

Para a produção de milho-verde comum ou doce, uma cultivar deve apresentar boas características agronômicas e satisfazer as exigências do consumidor. Assim, Kaukis \& Davis (1986), Pereira Filho et al. (2003) e Rodrigues (2007) consideram como ideais os seguintes caracteres: espigas longas e cilíndricas, de maior diâmetro, bem empalhadas, de sabugos claros e finos, com baixa retenção de "cabelos", maior longevidade póscolheita empalhada e despalhada, resistência a doenças e pragas, grãos distribuídos em fileiras uniformes, do tipo dentado, de cor amarela-creme e o pericarpo fino.

Quanto às características quantitativas comerciais para milho-verde Santos et al. (2005) e Câmara (2007) consideram importante a massa das espigas com palhas, uma maior percentagem e massa das espigas comerciais, o comprimento de espiga com palha superior a $22 \mathrm{~cm}$, quando destinadas às feiras livres e quitandas, o comprimento da espiga sem palha superior a 15 $\mathrm{cm}$ e o diâmetro superior a $30 \mathrm{~mm}$, quando estas se destinam aos supermercados.

O sucesso de um programa de melhoramento genético depende da herdabilidade, da escolha do método de melhoramento e da intensidade de seleção dos caracteres (Miranda Filho \& Nass, 2001; Cardoso et al., 2002). Nesse sentido, a seleção de genótipos superiores busca explorar ao máximo a variância genética aditiva e, com isso, atribuir aos caracteres selecionados, no próximo ciclo de seleção, um maior potencial (Bertan et al., 2004).

A seleção recorrente é utilizada para o melhoramento de populações ou para a criação de novas variedades. Apresenta como fases a obtenção de progênies, a avaliação destas progênies e a recombinação das progênies superiores divergentes, visando obter uma população que apresente variabilidade genética a ser explorada em ciclos futuros (Mackay \& Caligari, 2000; Miranda Filho \& Nass, 2001; Souza Junior, 2001). Embora as progênies de meios irmãos sejam as mais utilizadas no Brasil para a obtenção de populações melhoradas de milho, o método de irmãos germanos permite uma maior precisão experimental (Alves et al., 2002).

Como a disponibilidade de cultivares destinadas à produção de milho-verde é muito escassa no Brasil, a maioria dos trabalhos realizados apenas verificou a aptidão de híbridos e variedades comerciais, inicialmente recomendados para a produção de grãos ou silagem (Paiva Júnior et al., 2001; Rodrigues, 2007). Há escassez de informações sobre a obtenção de cultivares destinadas a produção milho-verde e estudos genéticos de características envolvidas com este produto (Rodrigues, 2007), bem como ainda há poucos estudos sobre o emprego de metodologias de seleção de progênie. Como as populações tropicais trabalhadas no Brasil apresentam elevada depressão por endogamia, justifica-se alocar recursos e tempo no melhoramento de populações (Rodrigues et al., 2001).

O presente trabalho teve por objetivos: avaliar o efeito do tamanho da espiga seca sobre a qualidade da progênie no estádio de milho-verde; avaliar o potencial de progênies de irmãosgermanos para a produção de milho-verde, visando selecionar as melhores progênies; estudar as relações entre espigas colhidas no ponto de milhoverde e de maturação de campo, estudar as relações das características comprimento de espiga com palha e massa de espiga sem palha com as demais características da espiga colhidas e avaliadas em ponto de milho-verde.

\section{MATERIALE MÉTODOS}

Os ensaios foram conduzidos na Fazenda Escola Capão da Onça, pertencente à Universidade Estadual de Ponta Grossa - UEPG, em Ponta Grossa - PR. Localizada a $880 \mathrm{~m}$ de altitude, latitude $25^{\circ} \mathrm{S} \mathrm{e}$ longitude $50^{\circ} 10^{\prime} \mathrm{W}$, possui um clima classificado como $\mathrm{Cfb}$, definido pelo sistema de Köppen, subtropical úmido, mesotérmico e sem estação seca definida, com geadas freqüentes no inverno. O relevo é suave ondulado e o solo do ensaio classificado como Latossolo Vermelho Distrófico típico (EMBRAPA, 1999).

A obtenção da população destinada à produção de milho-verde iniciou-se na safra 1997/ 1998 pela polinização manual das variedades Ita e Piranão pela variedade peruana Gigante Blanco Urubamba. A partir da mistura das sementes das duas populações híbridas foram realizados dois ciclos de seleção massal, cujas sementes resultantes foram semeadas manualmente na safra $2000 / 2001$, em seis faixas constituídas de duas fileiras, as quais foram alternadas com os híbridos duplos D 170 e AG 1051. Das fileiras da população segregante emasculadas antes da liberação do 
pólen foram coletadas as melhores espigas. Empregando-se as sementes híbridas, foram realizados dois ciclos de seleção massal, colhendose das melhores plantas, as espigas sadias, longas, de maior diâmetro, bem empalhadas, contendo de 8 a 12 fileiras bem definidas, constituídas de grãos longos, largos e espessos, critérios esses também utilizados para milho-verde.

Para a obtenção das progênies de irmãos germanos, no dia 01/11/2004, foram semeadas 35 progênies de meios-irmãos, sendo cada progênie constituída de uma única linha de plantas, com $20 \mathrm{~m}$ de comprimento, espaçada de $0,90 \mathrm{~m}$ entre si, com uma população de aproximadamente 45.000 plantas ha-1.

A partir de 20/01/2005, foram realizadas polinizações entre as plantas de todas as progênies de meio-irmãos, obtendo-se cerca de 1500 espigas, das quais, em ponto de maturação de campo, foram pré-selecionadas visualmente 1053 espigas, baseando-se no comprimento, diâmetro, bom empalhamento e sanidade. Em laboratório as mesmas foram despalhadas e mensuradas quanto ao comprimento, diâmetro, massa, número de fileiras por espiga, e após a debulha quanto ao diâmetro do sabugo, número e massa de grãos por espiga. De cada fileira foram selecionadas entre 4 e 8 espigas, utilizando-se como critério as mais longas, de maior diâmetro e massa de grãos, resultando em 190 progênies de irmãos germanos. O mesmo procedimento foi repetido, tomando-se as espigas intermediárias em ordem decrescente, resultando em 179 progênies, sendo destinado à instalação do primeiro ensaio. Em razão do pequeno espaço disponível para o armazenamento das sementes, de cada espiga selecionada foram separadas 120 sementes, as quais foram mantidas em geladeiras até o momento do semeio, sendo a metade utilizada para a implantação do teste de progênies e as restantes para a recombinação das progênies superiores.

Os testes de progênies foram realizados na safra 2005/2006, constituídos por 179 e 190 progênies pré-selecionadas e mais três híbridos de milho recomendados para a produção de milhoverde, os quais foram utilizados como testemunhas, sendo eles DKB 214, 2C577 e Tropical Doce.

O delineamento experimental utilizado foi o de blocos casualizados com duas repetições para as 179 progênies e três repetições para as 190 progênies. Cada parcela foi constituída de uma linha de $4 \mathrm{~m}$ de comprimento, com espaçamento entre linhas de $0,80 \mathrm{~m}$ e uma população aproximada de 50.000 plantas ha-1. Os blocos foram semeados com intervalo de 10 a 14 dias, visando otimizar as avaliações por ocasião da colheita. Para a adubação de base utilizou-se $300 \mathrm{~kg} \mathrm{ha}^{-1}$ da fórmula $\mathrm{N}_{2}-\mathrm{P}_{2} \mathrm{O}_{5}-$ $\mathrm{K}_{2} \mathrm{O}$ 05-25-25 e em cobertura $100 \mathrm{~kg} \mathrm{ha}^{-1} \mathrm{de}$ nitrogênio na forma de uréia aplicado em cobertura, entre os estádios vegetativos v4 e v8. O controle fitossanitário foi realizado conforme recomendação para a cultura. O ensaio composto por 179 progênies foi semeado em outubro e a colheita das espigas em ponto de milho-verde ocorreu na primeira quinzena de fevereiro. O ensaio composto por 190 progênies foi semeado em novembro de 2005, com as colheitas das espigas em ponto de milho-verde, ocorrendo na segunda quinzena de fevereiro e na primeira de março de 2006.

Do ensaio constituído de 179 progênies foram colhidas todas as espigas em ponto de milhoverde. Do ensaio constituído de 190 progênies, dentro de cada progênie foram coletadas 7 espigas comerciais em ponto de milho-verde e as demais em ponto de maturação de milho seco. Em laboratório, foram avaliadas 5 espigas quanto às seguintes características: comprimento de espigas com palha (CCP), diâmetro de espigas com palha (DCP), massa de espigas com palha (MCP), comprimento de espigas sem palha (CSP), diâmetro de espigas sem palha (DSP) e massa de espigas sem palha (MSP). As espigas de milho-verde sem palhas, baseando-se no seu formato, comprimento e diâmetro, bem como na distribuição, tamanho e formato dos grãos, foram classificadas em ruins, médias, boas, muito boas e excelentes. Além dessas características, foram observados aspectos como fileiras bem definidas, quantidade e comprimento de palha, cor do grão, espigas danificadas (doenças, insetos), sendo estes utilizados como critérios de descarte das progênies no momento da seleção.

Os valores obtidos a partir das características avaliadas foram submetidos à análise de variância e as médias comparadas e agrupadas pelo teste de Scott-Knott ao nível de 1\% de probabilidade, pelo programa SASM-Agri (Canteri et al., 2001).

As correlações entre as características comprimento, diâmetro e massa de espigas com e sem palha, colhidas e avaliadas no ponto de milhoverde, com as respectivas características das progênies no ponto de maturação de campo foram estimadas. Além disso, estudaram-se as correlações entre o comprimento de espigas com palha e a massa de espigas sem palha com as características diâmetro e massa de espigas com palha e comprimento e diâmetro de espigas sem palha, colhidas em ponto de milho-verde.

Para a estimativa da herdabilidade foi adotado o Método dos Componentes da Variância, através da esperança matemática dos quadrados médios da análise de variância, para progênies de milho em um ambiente, conforme o modelo descrito por Vencovsky \& Barriga (1992).

\section{RESULTADOS E DISCUSSÃO}

Os resultados da análise de variância demonstraram diferenças significativas ao nível de $1 \%$ de probabilidade (teste $\mathrm{F}$ ), nos dois ensaios, para comprimento, diâmetro e massa de espigas com e sem palha, em ponto de milho-verde. Para o ensaio constituído de 179 progênies de meios irmãos, derivadas de espigas secas de tamanho intermediário, a comparação das médias utilizando 
FERREIRA, R. et al. Seleção de progênies de irmãos germanos...

o teste de Scott-Knott resultou em três grupos de classificação para o comprimento e diâmetro da espiga, e quatro grupos para massa da espiga (Tabela 1). Para o ensaio constituído de 190 progênies derivadas de espigas secas maiores, a comparação das médias utilizando o teste de ScottKnott resultou em quatro grupos de classificação para o comprimento com palha e massa da espiga com e sem palha, e apenas três grupos para os caracteres comprimento sem palha e diâmetro da espiga com e sem palha (Tabela 2). De acordo com Cardoso et al. (2002) e Rodrigues (2007) essas diferenças de comportamento observadas, nos dois ensaios, sugerem a existência de variabilidade genética entre os genótipos.

TABELA 1 - Intervalos de classificação para cada grupamento (A, B, C, D), em cada característica, estabelecido pelo teste de Scott-Knott e percentagem de progênies classificadas em cada um dos grupos, a partir de 179 progênies de meios irmãos.

\begin{tabular}{|c|c|c|c|c|c|}
\hline \multicolumn{2}{|c|}{ Caracteres da Espiga } & \multirow{2}{*}{$\frac{A}{(32,50-27,43)}$} & \multirow{2}{*}{$\frac{B}{(27,38-25,30)}$} & \multirow{2}{*}{$\frac{C}{(25,20-20,40)}$} & \multirow{2}{*}{$\frac{D}{-}$} \\
\hline $\mathrm{CCP}^{(1)}$ & Intervalo & & & & \\
\hline$(\mathrm{cm})$ & $(\%)$ & 55,87 & 30,17 & 13,97 & \\
\hline \multirow{2}{*}{$\begin{array}{l}\mathrm{DCP}^{(2)} \\
(\mathrm{mm})\end{array}$} & Intervalo & $(63,50-57,20)$ & $(57,10-51,80)$ & $(51,50-40,00)$ & - \\
\hline & $(\%)$ & 14,53 & 37,43 & 48,04 & \\
\hline \multirow{2}{*}{$\begin{array}{c}\mathrm{MCP}^{(3)} \\
(\mathrm{g})\end{array}$} & Intervalo & $(445,50-370,17)$ & $(366,30-302,50)$ & $(300,30-235,70)$ & $(231,70-136,73)$ \\
\hline & $(\%)$ & 14,53 & 26,26 & 35,75 & 23,46 \\
\hline \multirow{2}{*}{$\begin{array}{c}\mathrm{CSP}^{(4)} \\
(\mathrm{cm})\end{array}$} & Intervalo & $(24,03-17,09)$ & $(17,80-15,20)$ & $(14,98-10,25)$ & - \\
\hline & $(\%)$ & 58,10 & 31,29 & 10,61 & \\
\hline \multirow{2}{*}{$\begin{array}{c}\mathrm{DSP}^{(5)} \\
(\mathrm{mm})\end{array}$} & Intervalo & $(52,25-41,50)$ & $(41,20-37,40)$ & $(37,20-31,25)$ & - \\
\hline & $(\%)$ & 59,22 & 31,84 & 8,94 & \\
\hline \multirow{2}{*}{$\begin{array}{c}\operatorname{MSP}^{(6)} \\
(\mathrm{g})\end{array}$} & Intervalo & $(302,42-230,60)$ & $(230,60-185,43)$ & $(182,90-142,40)$ & $(138,98-80,00)$ \\
\hline & $(\%)$ & 16,76 & 36,31 & 29,05 & 17,88 \\
\hline
\end{tabular}

(1), (2) e (3) - Comprimento, diâmetro e massa das espigas com palha;

(4), (5) e (6) - Comprimento, diâmetro e massa das espigas sem palha.

As testemunhas DKB 214 e 2C577 se localizaram no grupo A (Tabelas 1 e 2), para a maioria das características, enquanto que, o híbrido Tropical Doce, que é recomendado para a produção de milho-doce (enlatado), geralmente apresentou espigas menores, sendo classificado nos grupos inferiores.

Ao se comparar o efeito da seleção para espigas secas sobre os grupos de progênies de irmãos germanos de milho-verde formados pelo teste de Scott-Knott, verifica-se grande semelhança para MCP, CSP, DSP e MSP (Tabelas 1 e 2). Quanto ao CCP, a diferença pode ser devido ao número de grupos resultantes nos dois ensaios. Apenas para o caráter DCP, ocorreu uma maior percentagem de progênies no grupo $A$ derivadas das espigas secas maiores. Ao se comparar as médias das características das espigas de milho-verde, dos ensaios com 179 e 190 progênies de irmãos germanos, entre si e com a média das testemunhas, verificam-se grande similaridade para as características CCP, DCP, MCP, CSP e DSP, e diferenças para MSP (Tabela 3). Quanto à MSP, o ensaio com 179 progênies apresentou média inferior às testemunhas e ao ensaio com 190 progênies, o mesmo comportamento da massa de grão seco. Quanto à média das progênies selecionadas elas foram superiores às testemunhas, demonstrando a potencialidade da população que está sendo desenvolvida para atender a região de Ponta Grossa. Verifica-se nos dois ensaios (Tabelas $1 \mathrm{e}$ 2) que acima de $86 \%$ das progênies apresentaram comprimento da espiga com palha (CCP) acima de $22 \mathrm{~cm}$, portanto superiores ao comprimento mínimo sugerido por Câmara (2007) e Vieira (2007). O empalhamento de espigas é a característica mais importante para a comercialização destinada a feiras livres e quitandas (Oliveira et al., 1987; Paiva Júnior et al., 2001), pois além da proteção física da espiga contra o ataque de insetos e doenças (Rodrigues, 2007), é muito utilizada na elaboração de pratos a base de milho-verde, como a pamonha, por exemplo. 
FERREIRA, R. et al. Seleção de progênies de irmãos germanos...

TABELA 2 - Intervalos de classificação para cada grupamento (A, B, C, D), em cada característica, estabelecido pelo teste de Scott-Knott e percentagem de progênies classificadas em cada um dos grupos a partir de 190 progênies de meios irmãos.

\begin{tabular}{|c|c|c|c|c|c|}
\hline \multicolumn{2}{|c|}{ Caracteres da Espiga } & \multirow{2}{*}{$\frac{A}{(32,47-28,40)}$} & \multirow{2}{*}{$\frac{B}{(28,33-26,67)}$} & \multirow{2}{*}{$\frac{C}{(26,60-24,60)}$} & \multirow{2}{*}{$\frac{D}{(24,47-20,93)}$} \\
\hline $\mathrm{CCP}^{(1)}$ & Intervalo & & & & \\
\hline$(\mathrm{cm})$ & $(\%)$ & 24,87 & 37,82 & 26,42 & 10,88 \\
\hline \multirow{2}{*}{$\begin{array}{c}\mathrm{DCP}^{(2)} \\
(\mathrm{mm})\end{array}$} & Intervalo & $(66,33-52,07)$ & $(51,87-48,13)$ & $(47,98-40,92)$ & - \\
\hline & $(\%)$ & 55,96 & 29,53 & 15,51 & \\
\hline \multirow{2}{*}{$\begin{array}{l}\operatorname{MCP}(3) \\
(g)\end{array}$} & Intervalo & $(441,83-345,07)$ & $(341,13-281,73)$ & $(280,47-236,78)$ & $(234,33-144,17)$ \\
\hline & $(\%)$ & 12,93 & 47,67 & 21,24 & 18,13 \\
\hline \multirow{2}{*}{$\begin{array}{l}\operatorname{CSP}^{(4)} \\
(\mathrm{cm})\end{array}$} & Intervalo & $(21,07-16,27)$ & $(16,13-13,80)$ & $(13,53-10,75)$ & - \\
\hline & $(\%)$ & 69,43 & 24,35 & 6,22 & \\
\hline \multirow{2}{*}{$\begin{array}{c}\mathrm{DSP}^{(5)} \\
(\mathrm{mm})\end{array}$} & Intervalo & $(59,45-41,93)$ & $(41,73-39,00)$ & $(38,81-34,03)$ & - \\
\hline & $(\%)$ & 62,18 & 24,87 & 12,95 & \\
\hline \multirow{2}{*}{$\begin{array}{c}\mathrm{MSP}^{(6)} \\
(\mathrm{g})\end{array}$} & Intervalo & $(280,00-216,47)$ & $(214,42-175,17)$ & $(174,27-137,67)$ & $(134,53-83,95)$ \\
\hline & $(\%)$ & 16,06 & 51,30 & 22,80 & 9,85 \\
\hline
\end{tabular}

(1), (2) e (3) - Comprimento, diâmetro e massa das espigas com palha;

(4), (5) e (6) - Comprimento, diâmetro e massa das espigas sem palha.

Quanto ao DCP, acima de $51,96 \%$ das progênies de irmãos germanos foram superiores a $51 \mathrm{~mm}$ (Tabelas 1 e 2), cuja magnitude foi semelhante às obtidas por Vieira (2007), em espigas derivadas de híbridos, na mesma região.

Em relação à $M C P$, verificou-se que entre $12,93 \%$ e $14,53 \%$ das progênies de irmãos germanos apresentaram massa semelhante às testemunhas (Tabelas 1 e 2), valores estes similares aos obtidos por Vieira (2007), nas mesmas condições experimentais.

Para o comprimento da espiga sem palha (CSP), pode-se verificar que acima de $58,10 \%$ das progênies (Tabelas 1 e 2) apresentam valores acima de $15 \mathrm{~cm}$, o qual é recomendado por paiva júnior et al. (2001), Santos et al. (2005), Rodrigues (2007) e Vieira (2007).

Quanto ao DSP, característica responsável pela preferência dos consumidores pode-se verificar que a totalidade das progênies (Tabelas 1 e 2), apresenta média superior a $30 \mathrm{~mm}$, que é o padrão sugerido por Rodrigues (2007) e Paiva Júnior et al. (2001); e acima de $59,22 \%$ das progênies apresentaram valores superiores a $40 \mathrm{~mm}$, sugeridos por Santos et al. (2005) e Vieira (2007).

A MSP é uma característica importante para a comercialização em bandejas de isopor (Oliveira et al., 1987; Paiva Júnior et al., 2001; Alves et al., 2004; Rodrigues, 2007) e para a seleção de cultivares (Santos et al., 2005). Pelo menos 53,07\% das progênies (Tabelas 1 e 2) apresentam massa igual ou superior aos cultivares utilizados por Santos et al. (2005) e Vieira (2007).

A Tabela 4 mostra as relações existentes entre o comprimento da espiga com palha e da massa da espiga sem palha, entre si e com os demais caracteres avaliados. Verifica-se que os valores da análise de correlação $(r$ ) obtidos são similares aos observados por Oliveira et al. (1987) e Santos et al. (2005). O comprimento da espiga com palha pode ser favorecido pela seleção indireta para comprimento e massa sem palha. A massa da espiga sem palha pode ser beneficiada pela seleção indireta para diâmetro com e sem palha, comprimento e massa sem palha.

A herdabilidade mede a confiança do valor fenotípico como indicador do valor reprodutivo, pois ela não é apenas uma propriedade do caráter, mas também das progênies avaliadas (Rodrigues, 2007). A partir das progênies derivadas das 190 maiores espigas secas, foram estimados os valores de herdabilidade para comprimento $(0,60)$, diâmetro $(0,54)$ e massa $(0,56)$ das espigas com palhas, e para comprimento $(0,52)$, diâmetro $(0,46)$ e massa espigas $(0,57)$ sem palhas, refletem o bom controle local e a grande variabilidade genética presente nas progênies avaliadas em ponto de milho-verde. Os valores de herdabilidade foram inferiores aos obtidos por Rodrigues (2007), para as características comprimento $(0,89)$ e diâmetro $(0,59)$ da espiga sem palha. 
FERREIRA, R. et al. Seleção de progênies de irmãos germanos...

TABELA 3 - Comparação das características médias das espigas avaliadas e selecionadas em ponto de milho seco, das progênies avaliadas e selecionadas em ponto de milho-verde, com as médias das testemunhas (DKB 214, 2C577 e Tropical), nos ensaios com 179 e 190 progênies de meiosirmãos.

\begin{tabular}{|c|c|c|c|c|c|c|c|}
\hline Genótipos & $\begin{array}{c}\mathrm{CCP}^{(1)} \\
(\mathrm{cm})\end{array}$ & $\begin{array}{c}\mathrm{DCP}^{(2)} \\
(\mathrm{mm})\end{array}$ & $\begin{array}{c}\mathrm{MCP}^{(3)} \\
(\mathrm{g})\end{array}$ & $\begin{array}{c}\mathrm{CSP}^{(4)} \\
(\mathrm{cm})\end{array}$ & $\begin{array}{c}\mathrm{DSP}^{(5)} \\
(\mathrm{mm})\end{array}$ & $\begin{array}{c}\mathrm{MSP}^{(6)} \\
(\mathrm{g})\end{array}$ & $\begin{array}{c}M G^{(7)} \\
(\mathrm{g})\end{array}$ \\
\hline \multicolumn{8}{|l|}{ Milho seco } \\
\hline 1053 progênies avaliadas & - & - & - & 13,23 & 42,24 & - & 124,94 \\
\hline 179 progênies selecionadas & - & - & - & 12,69 & 46,78 & - & 123,39 \\
\hline 190 progênies selecionadas & - & - & - & 15,72 & 48,48 & - & 166,31 \\
\hline \multicolumn{8}{|l|}{ Milho-verde } \\
\hline 179 progênies avaliadas & 27,62 & 51,86 & 289,47 & 18,19 & 41,77 & 185,20 & - \\
\hline 35 progênies selecionadas & 29,44 & 56,36 & 364,46 & 20,57 & 44,96 & 232,35 & - \\
\hline Testemunhas & 27,72 & 56,47 & 372,17 & 19,80 & 43,83 & 217,77 & - \\
\hline CV $(\%)$ & 5,99 & 7,46 & 16,36 & 10,68 & 6,09 & 15,82 & \\
\hline 190 progênies avaliadas & 27,02 & 52,33 & 289,79 & 18,36 & 44,93 & 234,58 & - \\
\hline 62 progênies selecionadas & 27,77 & 55,67 & 336,72 & 17,88 & 45,08 & 218,73 & - \\
\hline Testemunhas & 26,38 & 52,24 & 327,89 & 16,79 & 42,30 & 184,24 & - \\
\hline CV (\%) & 5,21 & 6,12 & 14,16 & 9,50 & 6,80 & 14,92 & - \\
\hline
\end{tabular}

(1), (2) e (3) - Comprimento, diâmetro e massa das espigas com palha;

(4), (5) e (6) - Comprimento, diâmetro e massa das espigas sem palha.

(7) - Massa de grãos secos

TABELA 4 - Estimativas dos coeficientes de correlação ( $r$ ) entre comprimento da espiga com palha (CCP) e da massa das espigas sem palha (MSP) com os demais caracteres da espiga das 190 progênies no ponto de milho-verde.

\begin{tabular}{lll}
\hline Característica & CCP & MSP \\
\hline Comprimento da espiga com palha & - & $0,39^{*}$ \\
Diâmetro da espiga com palha & $0,36^{*}$ & $0,80^{* *}$ \\
Massa da espiga com palha & $0,57^{* *}$ & $0,92^{* *}$ \\
Comprimento da espiga sem palha & $0,58^{* *}$ & $0,78^{* *}$ \\
Diâmetro da espiga sem palha & $0,19^{\text {n.s. }}$ & $0,84^{* *}$ \\
Massa da espiga sem palha & $0,39^{*}$ & - \\
\hline${ }^{*} ;{ }^{* *}$ significativo a 5 e 1\% de probabilidade, respectivamente & &
\end{tabular}


A seleção simultânea de várias características oferece maior chance de sucesso do desenvolvimento de uma cultivar que satisfaça a exigência do consumidor (Rodrigues, 2007). Neste sentido, foram priorizadas as progênies que apresentaram espigas classificadas visualmente como excelentes, bem como as progênies inseridas no grupo A pelo teste de Scott-Knott das características MSP e CCP. Em seguida, foram selecionadas algumas progênies que se destacaram para CSP, MCP, DSP, vigor das plantas da progênie, menor incidência de doenças e pragas. Assim, foram selecionadas 62 progênies derivadas das espigas secas maiores e 35 progênies derivadas das espigas secas intermediárias, o que resultou, no geral médias poucos superiores às populações originais (Tabela 3 ).

Para a seleção de novos cultivares de milhoverde, além da utilização das características mensuradas da espiga, deve-se utilizar a aparência da espiga sem palha que agrade ao consumidor. $\mathrm{Na}$ população composta de 35 famílias de meios irmãos foram observados apenas $2,85 \%$ de progênies com espigas de milho-verde classificadas como excelentes. Entre as progênies de irmãos germanos, observou-se $3,91 \%$ de espigas excelentes para as progênies derivadas das 179 espigas secas intermediárias, e 17,37\% para as progênies derivadas das 190 espigas secas maiores. A avaliação de 537 famílias de meios irmãos, procedentes da recombinação entre as progênies selecionadas, resultou em 27,56\% progênies produzindo pelo menos uma espiga excelente, refletindo segundo Bertan et al. (2004) uma concentração de alelos favoráveis. Assim, a continuidade deste programa de seleção de milhoverde, poderá resultar no desenvolvimento de uma cultivar de baixo custo e com melhor adaptação às condições regionais.

Em razão da dificuldade da coleta no ponto de correto de milho verde e da grande concentração de trabalho em um curto espaço de tempo, verificouse a possibilidade de se correlacionar as características em ponto de milho-verde com o ponto de maturação de grãos. Assim, utilizando-se o ensaio composto de 190 progênies, observou-se uma baixa correlação entre as características das espigas avaliadas em ponto de milho-verde e as respectivas progênies colhidas no ponto de maturação de campo, cujos valores do coeficiente de correlação variaram de $r=0,05$ para massa da espiga sem palha a $r=0,15$ para massa da espiga com palha. Estes valores explicam os relatos de Silva et al. (1997), Almeida et al. (2005) e Câmara (2007) os quais verificaram que nem sempre as melhores cultivares destinadas a produção de grãos secos também são as melhores para a produção de milho-verde. Portanto, para a seleção de cultivares para milho-verde é necessário que as espigas sejam avaliadas no ponto de milho-verde.

\section{CONCLUSÕES}

A seleção das progênies baseada nas características comprimento de espigas sem palha e massa de espigas com palha, levou a seleção indireta para a característica comprimento de espigas com palha.

A seleção das características diâmetro de espigas com e sem palha, massa de espigas com palha e comprimento de espigas sem palha, levou a seleção de forma indireta da característica massa de espigas sem palha, pois estas estão positivamente correlacionadas.

Um ciclo de seleção utilizando irmãos germanos aumentou a proporção de progênies com espigas de milho-verde classificadas como excelente de $2,85 \%$ para $27,56 \%$.

\section{AGRADECIMENTO}

Ao Conselho Nacional de Desenvolvimento Científico e Tecnológico (CNPq) pela concessão da bolsa PIBIC.

\section{REFERÊNCIAS}

1. ALMEIDA, I. P. C. et al. Baby corn, green ear and grain yield of corn cultivars. Horticultura Brasileira, v. 23, n. 4, p. 960-964, 2005.

2. ALVES, G. F.; RAMALHO, M. A. P.; SOUZA, J. C. de. Alterações nas propriedades genéticas da população CMS-39 submetida à seleção massal para prolificidade. Revista Brasileira de Milho e Sorgo, v. 1, n. 3, p. 89-101, 2002.

3. ALVES, S. M. de F. et al. Avaliação de cultivares para o processamento de pamonha. Pesquisa Agropecuária Tropical, v. 34, n. 1, p. 39-43, 2004.

4. BERTAN, I. et al. Estimativa do ganho genotípico por meio de seleção em geração segregante de aveia. Scientia Agraria, v. 5, n. 1-2, p. 29-33, 2004.

5. CÂMARA, T. M. M. Rendimento de grãos verdes e secos de cultivares de milho. Revista Ceres, v. 54 , n. 311 , p. 8792, 2007.

6. CANTERI, M. G. et al. SASM - Agri: Sistema para análise e separação de médias em experimentos agrícolas pelos métodos Scott - Knott, Tukey e Duncan. Revista Brasileira de Agrocomputação, v. 1, n. 2, p.18-24, 2001.

7. CARDOSO, E. T.; SERENO, M. J. C. de M.; BARBOSA NETO, J. F. Heritability estimates for quality and ear traits in sweet corn. Crop Breeding and Applied Biotechnology, v. 2, n. 4, p. 493-498, 2002.

8. EMPRESA BRASILEIRADE PESQUISAAGROPECUÁRIA (EMBRAPA). Centro Nacional de Pesquisa de Solos. Sistema Brasileiro de Classificação de Solos. Brasília: Embrapa Solos, 1999. 412 p.

9. KAUKIS, K.; DAVIS, D. W. Sweet Corn Breeding. In: BASSET, M. J. (Ed.). Breeding vegetable crops. Westport: AVI, 1986. p. 475-519. 
FERREIRA, R. et al. Seleção de progênies de irmãos germanos...

10. MACKAY, I. J.; CALIGARI, P. D. S. Methods of increasing short term response to full-sib family recurrent selection in small populations. Euphytica, v. 113, n. 1, p. 53-64, 2000.

11. MIRANDA FILHO, J. B.; NASS, L. L. Hibridação no Melhoramento. In: NASS, L. L. et al. Recursos genéticos e melhoramento - plantas. Rondonópolis: Fundação de Apoio à Pesquisa Agropecuária do Mato Grosso - Fundação MT, 2001. p. 159-199.

12. OliVEIRA, L. A. A.; GRoszman, A.; COSTA, R. A. Caracteres da Espiga de Cultivares de Milho no Estádio Verde. Pesquisa Agropecuária Brasileira, v. 22, n. 6, p. 587-592, 1987.

13. PAIVA JÚNIOR, M. C. et al. Desempenho de cultivares para a produção de milho verde em diferentes épocas e densidades de semeadura em Lavras-MG. Ciência e Agrotecnologia, v. 25, n. 5, p. 1235-1247, 2001.

14. PEREIRA FILHO, I. A.; CRUZ, J. C.; GAMA, E. E. G. Cultivares para o consumo verde. In: PEREIRA FILHO, I. A. (Ed.). O Cultivo do milho-verde. Brasília: Embrapa Informação Tecnológica, 2003. p. 17-30.

15. RODRIGUES, F. Análise dialélica de linhagens visando à produção de milho verde. 2007. 51 p. Dissertação (Mestrado em Agronomia - Genética e Melhoramento de Plantas) Curso de Pós-Graduação em Agronomia, Universidade Federal de Lavras, Lavras, 2007.

16. RODRIGUES, M. C. et al. Comparison among Inbreeding Systems in Maize. Crop Breeding and Applied Biotechnology, v. 1, n. 2, p. 105-114, 2001.

17. SANTOS, I. C. et al. Comportamento de cultivares de milho produzidos organicamente e correlações entre características das espigas colhidas no estádio verde. Revista Brasileira de Milho e Sorgo, v. 4, n. 1, p. 14553, 2005.

18. SILVA, P. S. L.; BARRETO, H. E. P.; SANTOS, M. X. Avaliação de cultivares de milho quanto ao rendimento de grãos verdes e secos. Pesquisa Agropecuária Brasileira, v. 32, n. 1, p. 63-69, 1997.

19. SOUZA JUNIOR, C. L. de. Melhoramento de Espécies Alógamas. In: NASS, L. L. et al. (Ed.). Recursos Genéticos e Melhoramento - Plantas. Rondonópolis: Fundação de Apoio à Pesquisa Agropecuária do Mato Grosso Fundação MT, 2001. p. 135-158.

20. TSUNECHIRO, A.; DUARTE, J. O.; MATTOSO, M. J. Aspectos Econômicos da Comercialização e Custo de Produção. In: PEREIRA FILHO, I. A. (Ed.). O Cultivo do milho-verde. Brasília: Embrapa Informação Tecnológica, 2003. p. 170 182.

21. VENCOSVSKY, R.; BARRIGA, P. Genética biométrica no fitomelhoramento. Ribeirão Preto: Sociedade Brasileira de Genética, 1992. 496 p.

22. VIEIRA, M. de A. Cultivares e populações de plantas na produção de milho-verde. 2007. 78 p. Dissertação (Mestrado em Agronomia - Produção Vegetal) Curso de Pós-Graduação em Agronomia, Setor de Ciências Agrárias, Universidade Federal do Paraná, Curitiba, 2007.

Recebido em 11/04/2008

Aceito em 13/10/2008 